\title{
Sustainable Growth in Haiti: Creating Meaningful Change in the Developing World
}

\author{
Claire Elizabeth Haselhorst, Robert Merton Stwalley III* \\ Department of Agricultural \& Biological Engineering, Purdue University, West Lafayette, USA
}

Email address:

chaselho $a$ purdue.edu (C. E. Haselhorst), rms3@purdue.edu (R. M. Stwalley III)

${ }^{*}$ Corresponding author

\section{To cite this article:}

Claire Elizabeth Haselhorst, Robert Merton Stwalley III. Sustainable Growth in Haiti: Creating Meaningful Change in the Developing World. International Journal of Business and Economics Research. Vol. 7, No. 5, 2018, pp. 144-150. doi: 10.11648/j.ijber.20180705.13

Received: August 3, 2018; Accepted: September 7, 2018; Published: October 9, 2018

\begin{abstract}
Recent tragedies have placed a global spotlight on the county of Haiti, which many observers believe to be a nation mired in incurable poverty. Many organizations in the developed world have previously engaged in various projects and relief efforts to improve the living conditions in the country and develop the infrastructure of the nation. However, some observers have questioned the sustainability and beneficial results of these efforts. There is a reasonable concern that some of these projects generate more harm than good. Strategically, it is necessary to consider whether sustainable development occurs through these efforts, and if not, what changes can be made to improve the benefits from outside intervention for people living in the developing world. This paper will provide a framework for that evaluation, by looking at the history of development efforts in Haiti, primarily through examining the nation under a lens of food security and resource development, two commonly accepted metrics for economic development. The paper will then explore suggested means of making future efforts more sustainable and effective using techniques that have had proven success elsewhere within the developing world. Finally, the paper will examine the specific focused efforts of personnel associated with the Village of Hope, a successful educational and health care NGO mission in Gantier. It will be demonstrated that much of the success of the Village of Hope is based upon their recognition of these fundamental effective development techniques.
\end{abstract}

Keywords: Economic Development, Food Security, Haiti, Resource Development, Sustainable Growth

\section{Introduction}

The country of Haiti has a long history of instability and unrest. It is the poorest country in the Western hemisphere and one of the poorest countries in the world. In recent history, earthquakes and hurricanes have battered the countryside, and there has been no storage of human induced misery $[1,2]$. Although Haiti's problems seem intractable, there are no shortages of ideas about how to bring about improvement [3, 4]. Many developed countries and organizations based outside of Haiti have conducted efforts to aid its people [5, 6]. Some have sent supplies and others have deployed development projects within the region. These efforts have been aimed to increase the health, food security, and economic stability of the developing nation. They strive to overcome the previous tragedies of the past [7] and build a prosperous Haiti from the rubble of the past [8].
In the summer of 2016, a research team from the Purdue University Agricultural and Biological Engineering department spent a week in Port-au-Prince, Haiti with one of these organizations. Village of Hope $(\mathrm{VoH})$ is a nonprofit organization based in the United States. Its members have been actively working within the Haitian community surrounding Port-au-Prince since 1991. The Purdue team was able to stay at the VoH compound in the city center, visit some of the inner city projects they participate with, and collect information on the site of their flagship project known as the "Village of Hope" near Gantier, on the east edge of Ouest province. The team was also able to interview some of their in-country partners, learn about the history of their projects, and understand what sustainable development has looked like for their efforts.

The perspectives of the volunteers who have been working with $\mathrm{VoH}$ from the very beginning of the project were incredibly valuable when trying to understand the outsider's 
role and impact within Haitian society. Key questions were: Are these interventions from richer countries making a lasting difference? Is sustainable growth achievable through these methods? The consensus from the interviews conducted was, "yes and no." Positive developments had been seen in the communities the volunteers interacted with. Education, access to medical care, job placement, sources of safe water, and food security had all increased through the efforts of $\mathrm{VoH}$. Sustainable systems were developed by the organization, integrated into the community, and eventually handed-off to be operated by the local people using the service with minimal support from the American volunteers. However, for every successful project currently in operation, there were at least a dozen failed projects attempted by $\mathrm{VoH}$.

These experiences are not abnormal. There have been many benefits for local citizens from outside intervention in Haiti. However, there have also been many failures and unforeseen consequences. In the last decade, there has been a significant surge in "volunteer tourism" and a growing interest in development projects intended to aid Haitian growth and prosperity. It remains to be seen if these forces make a difference or if sustainable growth is possible under these circumstances. It is certainly unknown whether these volunteers are doing more harm than good.

\section{History of Efforts in Haiti}

Haiti has been a perpetual trouble spot within the western hemisphere for well over 100 years. Corruption, natural disasters, and a lack of investment have contributed to the economic malaise of the country for decades. Numerous external government agencies, faith-based organizations, and non-governmental organizations (NGOs) have been attempting to aid the Haitian people for a very long time, with little outward evidence of success.

\subsection{Food Security and Resource Development in Haiti}

In their 1994 report, "Policy Lessons from Natural Resources Projects in Haiti: A Framework for Reform," White and Gregerson [7] provide their observations on the state of the Haitian social environment.

"Rural poverty exists and has increased because of longstanding political, economic, and cultural divisions. The divisions occur among the poor rural majority, the small middle class, and the merchant and military elite. Taxes on rural production, coupled with a lack of government investments in public services and rural areas, reinforce the divisions. Indirectly, they lead to deforestation, land degradation, and poverty. More direct causes of poverty and degradation are the pervasive insecurity facing Haiti's people and deficit in production resources (land and capital). Another cause is the limited opportunity for expansion of off-farm employment that would reduce pressure on the land." [7]

The authors lament the effects of this social environment on the natural environment of the country. The depletion of Haiti's natural resources has made the poverty stricken country incredibly food insecure. Agricultural production in the country has struggled to develop sustainably. Failures in policy and economic reform have retarded growth and had little positive impact on conservation and environmental protection [7]. The authors attribute the stunted rural development in Haiti to a lack of "good" projects that encourage innovation and growth within the farming communities that can overcome the oppressive political policies placed around agricultural land activities. They explain that the limited growth of rural resources is, in part, due to misguided environmental policies, and they call for an evaluation and reform of local laws. White and Gregerson [7] appeal for lawmakers to "improve basic and essential social and physical infrastructure in rural areas," "strengthen local groups to manage rural development," "support development of rural microenterprises for off-farm employment," and "increase farmer social and economic security through legal means and productivity enhancement" [7]. They suggest that empowering the rural communities to manage their resources and develop their economies would increase the food security of the region and improve the management of local, natural resources.

An anthropological study was conducted in the 1980's by Mason, Ahlers, Henderson, Shorr, and Tabatabai [9] on the nutritional status of northern Haiti and how those considerations should be considered in rural development projects. The initial theory of the study was that the improvement of agricultural resources in the region would decrease the malnutrition of members of rural communities [9]. Improving the reliability and productivity of the local food sources should increase food security and access within the region. However, the study found that while this assumption was supported by the data, the reality of solving the food problems of the region was infinitely more complex than initially predicted. Agricultural improvements had a major impact on nutritional development, but the authors found that, infrastructure, education, economics, cultural interactions, and governmental policies also had significant effects on food security [9]. In general, it was demonstrated that the methods necessary to promote sustainable growth in a developing country like Haiti needed to be thoughtfully planned and considered, not attempted in a one off or ad hoc basis.

\subsection{The Recent Tragedies in Haiti}

In January, 2010, a powerful earthquake hit the country of Haiti. The disaster was estimated to have caused 230,000 deaths, 300,000 injuries, and the displacement of 2 million people [10]. The poverty and lack of infrastructure in the region were made apparent as global media outlets flooded with images of Haitian citizens being pulled from collapsed buildings and the results of the rapid spread of disease in the months that followed. The developed world felt called to action. Many countries sent aid. In the United States, the U.S Congress passed the Supplemental Appropriations Act of 2010 to make $\$ 1.14$ billion available for aid in reconstruction efforts in Haiti [10]. The U. S. Agency for International Development (USAID) was heavily involved with the allocation of funds for this international humanitarian effort. 
The department was allocated 40 percent (\$651 million) of the Supplemental Appropriations Act to assist in the development and construction of "(1) a power plant that will provide electricity for the new Caracol Industrial Park (CIP) in northern Haiti; (2) a new port near the CIP; and (3) permanent housing in new settlements in the Port-au-Prince, St-Marc, and Cap-Haïtien areas" [10].

In June, 2013, the United States Government Accountability Office (GAO) presented a study conducted by the department to the Foreign Affairs Committee of House of Representatives. The statement was delivered by David Gootnick, Director of International Affairs and Trade, was titled: "Haiti Reconstruction USAID Infrastructure Projects Have Had Mixed Results and Face Sustainability Challenges [10]" The testimony detailed the history of post-earthquake relief measures, the results of the USAID efforts, and concerns of sustainability for these efforts. The title of Mr. Gootnick's talk provided an adequate summary of his remarks.

The U.S. government released a five year strategy in 2011 to encourage reconstruction and long term economic development in Haiti called the Post-Earthquake USG Haiti Strategy: Toward Renewal and Economic Opportunity [11]. The focus of these efforts was in the capital and along the coast. These regions were deemed to be the hardest hit and had the potential to produce the greatest benefit from development. These regions can be seen in Figure 1, taken from the 2013 GAO summary. The three primary regions highlighted for development through the USAID efforts were St. Marc, Cap-Haitien, and Port-au-Prince. The figure also shows the locations of the port, power plant, and permanent housing projects overseen by the agency.

However, in the 2013 evaluation conducted by GAO, USAID had obligated 52 percent and only distributed 35 percent of the funds allocated in the 2010 budget [10]. Table 1 shows the state of the USAID funds as of June 30, 2013. Data from USAID and GAO is represented in sectors of development with columns depicting the allocated, total obligations, percentage obligated, disbursements, and percentage dispersed amounts of supplementary funding for USAID development activities in Haiti.

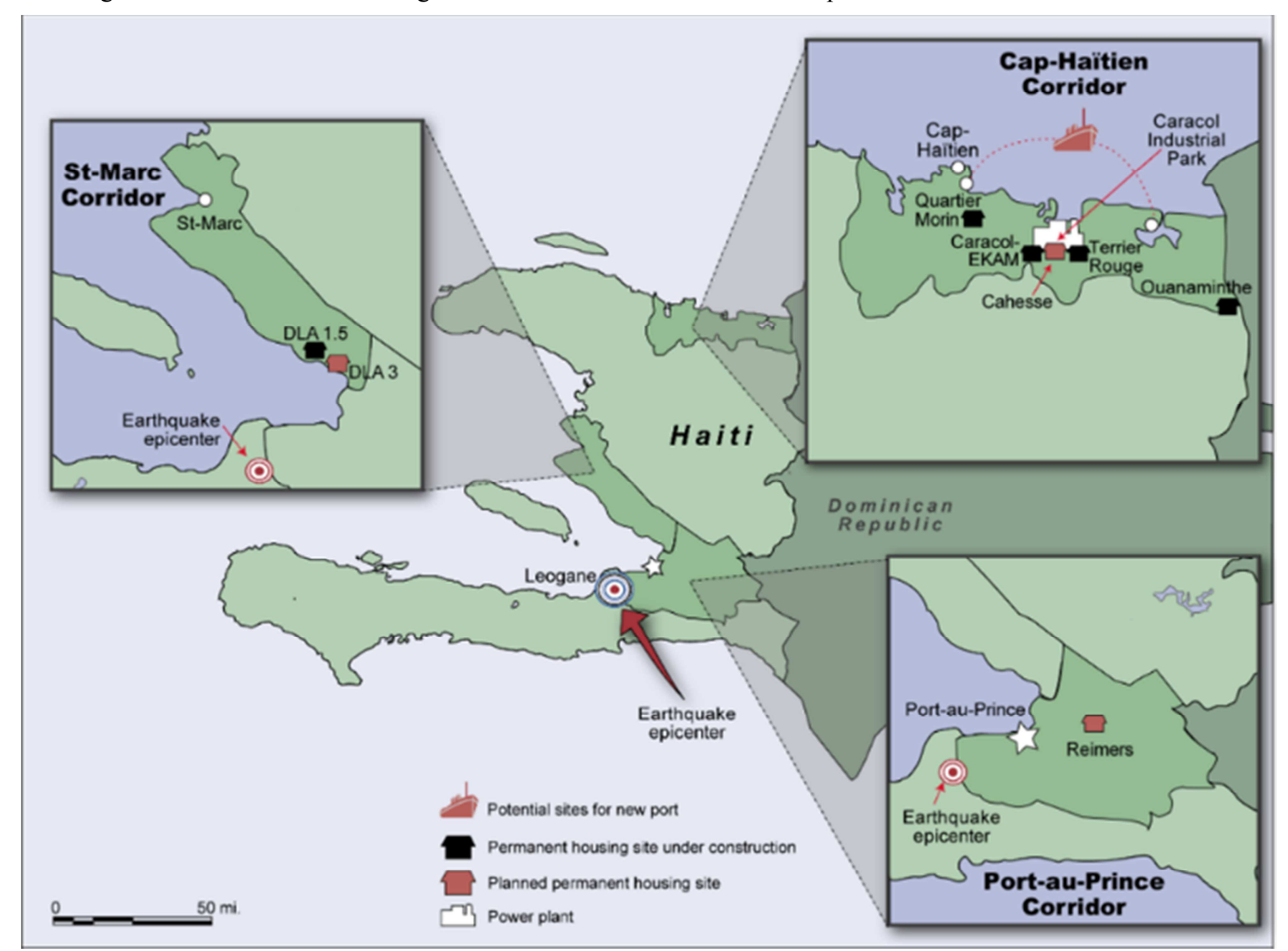

Figure 1. Development Corridors and Selected Sites Targeted by U.S. Post-Earthquake Assistance [10].

The testimony states that the power plant and establishment of a port in the Cap-Haïtien development region were delayed. A lack of technical expertise for planning, construction, and oversight were cited as major contributors to the delays. Feasibility studies conducted by multiple U.S. agencies stated that "more studies should be undertaken to identify the additional economic, environmental, technical, and other information necessary to make a final site selection and design the port" [10]. "USAID officials also initially estimated that port construction would take 2.5 years but have since learned 
that port construction may take up to 10 years, depending on the complexity of the port designed" [10]. The factors for sustainable economic development, through the establishment of this port, required the consideration of many unforeseen conditions that the members of USAID had initially underestimated. The dependence on the success of the CIP industrial park attached to the port and the economic environment of the region also threatened the success of the overall project [10].

Additionally, the establishment of permanent housing for earthquake victims was a slow moving effort with questionable sustainability. As planning and contracting for the permanent housing began to move forward, multiple changes and additions to the building plans by the Haitian government increased the projected cost of construction by 193 percent per unit [10]. These changes created massive delays in the housing project and decreased the number of housing units that could be built.

"As of August 2013, USAID had reduced the number of houses it expects to complete, and therefore the number of beneficiaries, by more than 80 percent. Of the 15,000 houses that it originally planned, USAID expects that only 2,649 will be completed across eight settlement sites." [10]. USAID also ran into issues with land acquisition for these projects. Land titling issues and difficulties with partnering NGOs and other donors were cited in the testimony as major setbacks for the housing development [12].

Table 1. USAID Sector Activities and Amounts of Supplemental Funding Allocated, Obligated, and Disbursed as of June 30, 2013 [10].

\begin{tabular}{|c|c|c|c|c|c|}
\hline Sector of USAID Activity (in millions of US\$) & Allocated & Obligations & $\%$ Obligated & Disbursements & $\%$ Disbursed \\
\hline Shelter & 83.10 & 49.20 & 59.00 & 40.00 & 48.00 \\
\hline Energy & 135.10 & 51.90 & 38.00 & 36.40 & 27.00 \\
\hline Ports and Transportation & 84.20 & 4.30 & 5.00 & 4.10 & 5.00 \\
\hline Food Security & 82.50 & 59.60 & 72.00 & 26.00 & 32.00 \\
\hline Health and disabilities & 99.40 & 38.40 & 39.00 & 18.30 & 18.00 \\
\hline Governance and rule of law & 120.40 & 95.40 & 79.00 & 72.60 & 60.00 \\
\hline Operating and other expenses & 46.20 & 37.20 & 81.00 & 32.20 & 70.00 \\
\hline
\end{tabular}

\begin{tabular}{|c|c|c|c|c|c|c|c|c|}
\hline \multicolumn{9}{|l|}{ Dollars in millions } \\
\hline \multirow{2}{*}{$\begin{array}{l}\text { Sector of USAID Activity } \\
\text { Shelter }\end{array}$} & \multicolumn{2}{|c|}{ Allocated } & \multicolumn{2}{|c|}{ Total obligations } & \multirow{2}{*}{$\begin{array}{l}\text { Percentage obligated } \\
59\end{array}$} & \multicolumn{2}{|c|}{ Disbursements } & \multirow{2}{*}{$\begin{array}{l}\text { Percentage disbursed } \\
48\end{array}$} \\
\hline & $\$$ & 83.1 & $\$$ & 49.2 & & $\$$ & 40.0 & \\
\hline Energy & $\$$ & 135.1 & $\$$ & 51.9 & 38 & $\$$ & 36.4 & 27 \\
\hline Ports and Transportation & $\$$ & 84.2 & $\$$ & 4.3 & 5 & $\$$ & 4.1 & 5 \\
\hline Food Security & $\$$ & 82.5 & $\$$ & 59.6 & 72 & $\$$ & 26.0 & 32 \\
\hline Health and disabilities & $\$$ & 99.4 & $\$$ & 38.4 & 39 & $\$$ & 18.3 & 18 \\
\hline Governance and rule of law & $\$$ & 120.4 & $\$$ & 95.4 & 79 & $\$$ & 72.6 & 60 \\
\hline TOTAL & $\$$ & 651.0 & $\$$ & 336.0 & 52 & $\$$ & 229.5 & 35 \\
\hline
\end{tabular}

Source: OAO analysis of USAID 2010 data.

In 2015, the GAO released a new report on the Haiti Reconstruction to congressional requesters entitled "USAID Has Achieved Mixed Results and Should Enhance Sustainability Planning." The document stated that as of September 2014, USAID had distributed $54 \%$ of its $\$ 1.7$ billion of reconstruction funds, and the mission's time table had been extended for another three years [12]. The sustainability issues and development struggles cited in the 2013 report were still present in the reconstruction activities that the GAO evaluated for the 2015 report. The flaws in the initial plan and execution of the U.S. post-earthquake relief effort continued to cause delays and increase the estimated cost of development in the region. Of the six projected outcomes for the "initial key infrastructure activities" (energy, health and disability, shelter, ports, and food security) for the Haiti mission, five had been significantly decreased, and four had suffered major delays [12]. "Mission officials said that factors such as lack of staff with engineering expertise, unrealistic planning, and Haitian government design changes contributed to cost overruns and delays." [12] The report showed the development of the USAID efforts from 2011 to 2015. The six infrastructure goals were now supported by 17 non-infrastructure activities aimed to develop human resources alongside the physical changes to the country [12]. For example, the food security efforts focused on supporting farmers in the northern and western regions of the country by promoting programs to develop agricultural productivity, while USAID improved the roads in these areas [12].

The USAID post-earthquake efforts were large, wide-spread, and well-meaning. However, the complexity of sustainable growth was not accounted for in the initial relief plans. The struggle to provide meaningful, long lasting change faltered under a lack of local understanding and appropriate preparation. As the project has continued, lessons have been learned and the efforts of USAID have become more complex. However, mixed results and project delays still plague the system [12]. The massive humanitarian effort still lacks the nuance to be considered a well-targeted effort.

\subsection{An Emerging Danger to Progress}

Before the earthquake, there were an estimated 10,000 NGOs working in Haiti providing $80 \%$ of the country's utilities [13]. This brought significant resentment and distain from many of the Haitian people, whose interests and culture 
were being overlooked by the foreign organizers. This volume of NGO involvement was already shown to be a hindrance to the long term development of Haiti, given the lack of organization and local oversight for these groups.

After the 2010 earthquake, Haiti saw a flood of support from NGOs, in addition to government aid. The number of active NGOs in the area bloomed to a literally countless number [13]. The efforts of these organizations were smaller scale, providing lifesaving initiatives that targeted communities and provided immediate relief in some of the hardest hit regions. Many lives were saved by the volunteers who flocked to Haiti, and the country continues to benefit from the stream of outside support that is still seen today. However, local oversight and guidance of these groups has declined in recent years. This has resulted in scattered, ineffective project outcomes that fail to address the needs of the Haitian people.

Christopher Garland remarked on a troubling trend that he observed in the volunteers that he worked with after the earthquake in the third quarter 2015 issue of Social and Economic Studies [14]. Garland described the behavior of some of the aid workers as intrusive and detrimental to the work that was being done. This trend has continued to grow, and the establishment of 'volunteer tourism' has drastically shaped the state of NGO involvement in Haiti. Garland particularly notes the use of photography by these 'voluntourists' and the consequences of their actions. NGOs have little oversight from the Haitian government, and many had been tailoring their activities to cater to poverty tourism long before the earthquake [14]. The use of photography is an incredibly powerful tool for these groups to generate interest and funding. While the intentions of many of these efforts are not malicious, the outcomes of 'volunteer tourism' have been disorganized, short-sighted efforts that have little benefit to the communities they are meant to aid, while exploiting the images of those living in poverty, often without the permission of those being photographed [14]. The ill will and wasted resources generated through this phenomenon have the potential to dramatically stunt or hinder growth within Haiti and increase the country's dependence of foreign aid.

\section{Sustainable Growth in the Developing World}

There are some sustainable changes occurring in Haiti. A portion of the development projects from outside governments and NGOs are actually helping. However, only the utilization of smart strategic assistance design and well executed tactical deployment can lead to measurable progress. These efforts are looking for ways to integrate new ideas into communities and decrease the overall dependence on foreign aid and relief efforts. Many of these advances are gained through cultural understanding and social interrelations.

\subsection{The Diffusion of Innovations Theory}

The Diffusion of Innovations theory explores the necessary atmosphere for the adoption of technology and innovation into developing communities. "Diffusion of Innovations: A World Tour" published in the 2004 Journal of Health Communications [15] shows three examples of sustainable growth and change through cultural understanding and mindful planning. The paper states that an understanding of the local culture and attention to how patterns of behavior disperse through a community are vital in producing lasting change. The theory states that the "trusted opinion leaders" are integral to the adoption of new ideas and practices [15]. New information may be rejected outright by an entire community, if the leaders of the community are not involved in the efforts. This process can be delicate and take a lot of time, but it is vital for progress in many developing regions. The Diffusion of Innovations theory also illustrates the power of small scale improvements within a community.

The example cited in the Barker paper was the utilization of kitchen gardens in Nepal to improve vitamin A nutrition. A USAID project funded the establishment of kitchen gardens for selected families within various rural regions of Nepal [15]. The goal of the project was for these families to lead by example. The dispersion method used in this case was an "if it works for my neighbor, it will work for me" mentality. Within a year, the number of kitchen gardens in the region increased tenfold, and the increases of vitamin A in the diets of the local people were reflected in the decreases in night blindness and improvements in general health [15]. The Diffusion of Innovations theory shows that lasting change can be found in simple answers. However, cultural understanding and community integration are vital for sustainable growth with these projects.

\subsection{Social Cohesion and Economic Development}

The perspectives of Diffusion of Innovations theory are also reflected by the 2012 publication by the Organization for Economic Co-operation and Development (OCED) [16] on the roles of social cohesion in the development of the global economy. The globalization of the modern age has created many opportunities for developed and developing countries alike. Wealth and improvement opportunities are being made available to poverty stricken nations whose untapped resources and underutilized potential can be used to compete in the global marketplace [16]. However, there are still challenges facing these efforts. Barriers for countries like Haiti to seize these opportunities include language, religion, lack of education or skilled workers, and cultural traditions [16]. These barriers to business do more than harm Haiti's economic potential. They also hinder the potential growth of local business ventures in the developed world [16]. Responsible international economic partnerships can be mutually beneficial and promote sustainable advancement for both parties, if properly nurtured and instituted in a responsible manner.

These responsible partnerships are reflected by Leonard and Gonzalez-Perez in their book International Business, Sustainability and Corporate Social Responsibility [17]. The authors review the history of corporate social responsibility 
(CSR) and the value of these business practices in international development. CSR is a vital aspect of sustainable growth within a company or business venture that developed in the $1950 \mathrm{~s}$, and it has become integral to the growth models of many respectable companies [17]. These values are incredibly important to uphold in developing countries. The promotion of socially responsible international business ventures can encourage lasting, sustainable growth in Haiti and many other countries. This growth should decrease the dependency on foreign aid in the developing world.

\section{Observations at the Village of Hope}

Many of the observations made by the Purdue ABE team in Port-au-Prince and at the Village of Hope campus reflected the literature's findings. While flying into the Port-au-Prince airport, the remaining rubble and destruction for the 2010 earthquake still paints a bleak and stirring picture. The plane itself was filled with two different volunteer groups eager to participate in the volunteer tourism that the country is now known for. They were already taking pictures and singing songs in the airport, clearly irritating some of the domestic airport staff members. The groups were a buzz with their plans to paint houses and build a church in a remote village. All of the Haitian residents observed looked at them with irritation, but they were clearly trying to be pleasant to some of the only tourists that they ever see in their country. The situation was incredibly awkward and very uncomfortable.

The team met the local VoH organizers in the parking lot. There was considerably less fanfare in this meeting than with other similar mission team meetings occurring simultaneously. The local team consisted of both Americans and Haitians. They considered it their business to run the Village of Hope campus and support local efforts like food banks and orphanages within the city. The primary focus of efforts during the week of the Purdue ABE team visit was the collection of data for future senior capstone engineering design projects that Village of Hope sponsors through the department. $\mathrm{VoH}$ is incredibly passionate about educational development and aims to increase their impact by partnering with educational institutions in the U.S.

$\mathrm{VoH}$ received the land that became their campus in 1991. In 25 years, they have built a K-12 school, a health clinic that services the local community, food programs for their students and the families of their students, and a clean drinking water supply for the neighborhood they reside in. The school is the main focus of the mission. They only admit incoming kindergarten students and educate them through secondary school. The graduating rate in 2017 was 54 percent, and this makes $\mathrm{VoH}$ one of the top primary and secondary educational institutions in the country.

$\mathrm{VoH}$ focuses on teaching their students marketable skills to improve the concentration of skilled labor in the area and foster the entrepreneurial spirit that seems ever present in the people of Haiti. Many of the VoH students have continued on to be translators, teachers, business owners, and members of other skilled professions. All of the other efforts on the campus focus on ensuring that the students are healthy and happy so that they have the greatest opportunity to learn in a positive, nurturing environment.

Interviews with the principal of $\mathrm{VoH}$ helped the team understand why some of the projects had failed in the past. The skeletons of wasted efforts littered a portion of campus. It was explained that each of these projects failed, because they were not integrated into the school effort. The local interest and value added to the school's mission from these projects was not high enough to justify maintaining these projects. They were eventually discarded for more pressing matters and valuable endeavors.

Within the city of Port-au-Prince, the team was able to visit the operational site of another organization's project. This endeavor was an orphanage for mentally and physically handicapped individuals. The average age of a resident of the orphanage was approximately 50 , with a youngest resident approximately five years old. Many of the people living in the orphanage were victims of the 2010 earthquake that could no longer care for themselves. The project was initially developed by the outside sponsors, but it had transitioned into local management in recent years. The religious group that took control of the effort had stopped accepting new charges and was working to transition the project into retirement. This orphanage was originally developed to address the very real needs of the mentally and physically handicapped living in a developing nation like Haiti. The drive behind the project was grounded in an important and rarely considered local issue. However in 2016, flaws within the initial planning and implementation of the facility were painfully obvious. The facility was under-developed, under-funded, and required retrofitting to meet the needs of the current residents. Community integration and staff training to support the disabled charges of the facility were sorely lacking. Misinformation and cultural biases toward those with mental and physical impairments was leading to substandard care for the residents. This facility lacked an overall support system to aid the staff and help provide a better life for the clientele. The project had gone into serious decline, because the local organization running the facility felt that they could better serve the community by focusing their efforts elsewhere. The original project was well-meaning, but it lacked sustainability. After the foreign administrative efforts were turned over to local managers, the project could no longer function effectively and began to deteriorate severely. The downfall of this orphanage reflected the sentiments expressed throughout the literature. Without consideration of local interests and community investment, development ventures conducted by outside parties in regions like Haiti lack sustainability and efficacy.

\section{Conclusions}

In spite of some earlier missteps, the growth of the campus of $\mathrm{VoH}$ is a learning example of how efforts should be conducted in Haiti. Strategies that focus on increasing 
opportunities for economic development and advancement that are supported by health care efforts and increasing access to sources of food can have a lasting impact on a community. VoH sustainably provides water, education, and healthcare to the community of Gautier in a manner accepted by the local population. Malnutrition and poverty are immediate concerns in nations like Haiti, but aid endeavors should not be blinded by these facts and ignore the issue of sustainability. The people of Haiti are capable and resourceful people. When given access to the tools needed to develop their nation, they will build-up their communities better than any outside influence ever could. The current struggles of the country are a temporary problem that could use outside assistance. However, the sources of this assistance need to remember the 'temporary' part of the temporary problem. Outside aid can only promote sustainable growth, if it focuses on developing projects that are needed and accepted by the local population and lead to lasting change.

\section{Acknowledgements}

Portions of this work have been supported by the Village of Hope - Haiti and Advent Lutheran Church - Boca Raton. The generous contributions of the Purdue University Agricultural \& Biological Engineering Department are hereby also gratefully acknowledged.

\section{References}

[1] O'Grady, M. A. (2015). Diagnosing what ails Haiti's economy. Wall Street Journal. 10/11/2015.

[2] The World Bank. (2014). Living conditions in Haiti's capital improve, but rural communities remain very poor. http://www.worldbank.org/en/news/featuer/2014/07/11/while-1 iving-conditions-in-porte-au-prince-are-improving-haiti-count ryside-remains-very-poor.

[3] Merilus, J. Y. (2015). Rural development: the economic potentials of Haiti's "Lakou" system. Focus on Geography 58 (1). pp 36-45.

[4] Dumay, H. (2012). Haitian higher education, funding, and economic development: the missing links. Haiti Perspectives 1 (1). pp 29-35.

[5] Sapat, A. \& Esnard, A. (2015). Directory of non-governmental organizations involved in Haiti's post-disaster recovery. https://fau.edu/spa/research/diaspora/sapat-and-esnard-director y-of-organizations-haiti-recovery-8-17-2015.pdf.

[6] Koa, C. (2016). Haiti's multi-billion dollar humanitarian aid problem.

https://www.huffingtonpost.com/young-professionals-in-forei gn-policy/haitis-multi-billion-doll_b_8207494.html.
[7] White, T. A., \& Gregersen, H. M. (1994). Policy lessons from natural resources projects in Haiti: A framework for reform. Retrieved http://ageconsearch.umn.edu/bitstream/11901/1/pb9.pdf.

[8] Chambers, J. (2016). Haiti needs new approach to make aid effective, bring jobs, and skills: ex-Prime Minister. https://www.reuters.com/article/us-myanmar-journalists-trial-s pecialrepo/special-report-how-myanmar-punished-two-reporte rs-for-uncovering-an-atrocity-idUSKCN1LJ167.

[9] Mason, J. B., Ahlers, T., Henderson, C., Shorr, I. J., \& Tabatabai, H. (1985) Identifying nutritional considerations in planning a rural development project in N. Haiti. Ecology of Food and Nutrition, 18:1, 1-17, DOI: 10.1080/03670244.1985.9990910.

[10] GAO. (2013). Haiti Reconstruction USAID Infrastructure projects have had mixed results and face sustainability challenges. Retrieved from

http://www.gao.gov/assets/660/658445.pdf.

[11] GAO. (2013). Post-Earthquake USG Haiti Strategy: Toward Renewal and Economic Opportunity Retrieved from http://www.gao.gov/assets/660/658445.pdf.

[12] GAO. (2015). Haiti Reconstruction USAID has achieved mixed results and should enhance sustainability planning. Retrieved from http://www.gao.gov/assets/680/670616.pdf.

[13] Edmonds, K. (2013). Beyond Good Intentions: The Structural Limitations of NGOs in Haiti. Critical Sociology, 39 (3), pp 439-452.

[14] Garland, C. (2015). The visual rhetoric of 'voluntourists' and aid workers in post-earthquake Haiti. Social and Economic Studies, 64.3/4, 79-102. Retrieved from http://search.proquest.com.ezproxy.lib.purdue.edu/docview/18 30731057? OpenUrlRefId=info:xri/sid:primo\&accountid=1336 0.

[15] Barker, K. (2004). Diffusion of innovations: A World Tour. Journal of health and communication, 9:S1, pp 131-137, DOI:10.1080/10810830490271584.

[16] OECD. (2012). Perspectives on global development 2012: Social cohesion in a shifting world. Retrieved from http://www.oecd-ilibrary.org.ezproxy.lib.purdue.edu/perspecti ves-on-global-development-2012_5kgfl pctjls2.pdf?contentTy $\mathrm{pe}=\% 2 \mathrm{fns} \% 2 \mathrm{fOECDBook} \% 2 \mathrm{c} \% 2 \mathrm{fns} \% 2 \mathrm{fBook} \&$ itemId $=\% 2 \mathrm{fc}$ ontent $\% 2$ fbook $\% 2$ fpersp_glob_dev-2012-en\&mimeType $=$ app lication $\% 2$ fpdf\&containerItem $\bar{I} d=\% 2$ fcontent $\% 2$ fserial $\% 2 \mathrm{f} 22$ $224475 \&$ accessItemIds $=\&$ option6=imprint\&value $6=\mathrm{http} \% 3 \mathrm{a}$ $\% 2 \mathrm{f} \% 2$ foecd.metastore.ingenta.com $\% 2$ fcontent $\% 2$ fimprint $\% 2$ foecd.

[17] Leonard, L., \& Gonzalez-Perez, M., A., (2013). International Business, Sustainability and Corporate Social Responsibility. Published by Emerald Group Publishing Limited. Retrieved from http://ebookcentral.proquest.com/lib/purdue/detail.action?docI $\mathrm{D}=1142043$. 